\title{
Toll-like receptors as an innate immunity bridge to neuroinflammation in medulloblastoma
}

\author{
Danuta Maslinska ${ }^{1,2}$, Milena Laure-Kamionowska', Slawomir Maslinski \\ 1Department of Experimental and Clinical Neuropathology, Mossakowski Medical Research Centre, Polish Academy of Sciences, Warsaw, \\ 2Department of General and Experimental Pathology, Warsaw Medical University, Warsaw, Poland
}

\begin{abstract}
The relationship between inflammation, immunity and cancer is widely accepted but mechanisms mediating this relationship remain unknown. Our present study was undertaken to examine the presence and distribution of Toll-like receptors (TLRs) in necrotic areas of medulloblastoma. These receptors fulfil the criteria postulated for the receptors of innate immunity and signalling from TLRs induces synthesis of various pro-inflammatory cytokines, enzymes and mediators. The study was performed on human medulloblastoma samples containing areas of necrosis within the tumour and/or within the normal nerve tissue at the periphery of the tumour. Proteins of four TLRS: TLR 2, 3, 4 and 9 were detected in the tissue with the immunohistochemical method using the specific antibodies. Two types of necrotic areas were found. In the first type, the area of dead cells was surrounded by undifferentiated medulloblastoma cells. A lot of these cells expressed TLR 2 and TLR 3 antigens. TLR 2 was also expressed on the wall of de novo formed blood vessels that fill tumour regions already cleared from dead cells. The second type of necrotic areas were found at the periphery of the tumour and composed of normal nerve tissue cells. TLR 2, TLR 3 and TLR 9 were detected in hypertrophic glia cells. Our findings show a new function of TLRs as sensors of pathogens released by medulloblastoma dead cells. This new function may provide a key link connecting innate immunity, neuroinflammation and angiogenesis in the tumour.
\end{abstract}

Key words: medulloblastoma, neuroinflammation, innate immunity, Toll-like receptors.

\section{Introduction}

Medulloblastoma is the most common primary brain tumour occurring in children with a male preponderance. In the last few years, whole-genome gene expression studies have provided strong molecular evidence supporting the notion that medulloblastomas represent a heterogeneous disease. Molecular subgroups of medulloblastoma have been identified based on the expression profile of specific sets of genes $[15,27]$. However, the major biological factors and mech- anisms that affect homeostasis and underline pathogenesis of the tumour subtypes remain unclear. Both genetic and epigenetic factors have been shown to influence the host response which may contribute to the growth of tumours.

Tumorigenesis is a multi-step process involving the alteration of a number of key cellular properties including uncontrolled proliferation, vascularisation (angiogenesis) and subsequent invasion and migration of tumour cells into the surrounding tissues [13]. The role of inflammation is especially important. However, while 
the normal inflammatory cascade is self-limiting and crucial for host protection against invading pathogens or in the repair of damaged tissue, a wealth of evidence documents that chronic inflammation is the engine driving carcinogenesis. In the early neoplastic process, inflammatory cells are recognizable tumour promoters, producing an attractive environment for tumour growth, facilitating genomic instability and promoting angiogenesis. Later in the tumorigenic process, neoplastic cells also divert inflammatory mechanisms to favour neoplastic spread and metastasis. The relationship between inflammation, immunity and cancer is widely accepted but mechanisms mediating this relationship remain unknown. Understanding the molecular processes of these cellular phenotypic changes may be critical to develop novel therapies. Central to mediating such changes is the interaction between cell surface receptors and their cognate ligands, which through intracellular signalling induce alterations in gene expression of the cells.

In this context, our present study was undertaken to examine the presence and distribution of Tolllike receptors (TLRs) in necrotic areas of medulloblastoma. These receptors fulfil the criteria postulated for the receptors of innate immunity called pattern-recognition receptors (PRR). Signalling from TLRs involves transcription factors that are activated and trans-located into the cell nucleus to induce new genes that encode synthesis of various pro-inflammatory cytokines, enzymes and mediators $[1,7,17,19,25,29]$. TLRs recognize highly conserved molecules present in microorganisms but they can also respond to some endogenous pathogens released by the host necrotic tissue. We suspected that medulloblastoma necrotic areas could be a source of unknown tumour pathogens that could be ligands for TLRs. Therefore, knowledge of TLRs distribution in medulloblastoma may shed some light on the relationship between the tumour and its harmful effect on the surrounding normal nervous tissue.

\section{Material and methods}

Medulloblastoma samples containing areas of necrosis within the tumour and/or within the normal nerve tissue at the periphery of the tumour, were selected from the brain paraffin blocks of the patients who died at different ages of life (1-5, 17, 37 years). Paraffin blocks of the tissue were drawn from archives of the Institute of Medical Research Centre, Polish Academy of Sciences, Warsaw, Poland and cut to serial sec- tions $10 \mu \mathrm{m}$ thick, stained with $\mathrm{H} \& \mathrm{E}$ for routine histological examination and used for immunohistochemical study.

\section{Immunohistochemistry}

Immunohistochemistry was performed using the avidin-biotin-peroxidase complex system, according to the manufacturer's recommendations (Vectastain Elite $A B C$ Peroxidase Kit; Vector Laboratories).

Briefly, sections were dewaxed and hydrated through descending alcohols to water. For non-enzymatic antigen retrieval, sections were heated in $0.01 \mathrm{M}$ sodium citrate buffer $\left(\mathrm{pH} \mathrm{6.0)}\right.$ ) to $95^{\circ} \mathrm{C}$ and allowed to cool for 20 min at room temperature and washed with PBS. Then, sections were incubated in methanol/3\% $\mathrm{H}_{2} \mathrm{O}_{2}$ solution for $20 \mathrm{~min}$ to quench endogenous peroxidase. Washed again in PBS and blocked with a solution containing PBS $/ 5 \%$ normal serum of goat, rabbit or mouse for $2 \mathrm{~h}$ at room temperature, sections were incubated overnight at $4^{\circ} \mathrm{C}$ in solutions of primary antibodies listed in Table I.

Immunoreactions were visualized using biotinylated secondary antibodies and ABComplex/HRP or an alkaline phosphatase-avidin-biotin conjugate. Then, sections were lightly counterstained with Mayer's haematoxylin. Numbers of immunopositive cells were counted in each of five serial sections under light microscope (magnification $\times 200$ ) as previously described $[17,25]$.

For negative controls, primary antibodies were replaced with an appropriate isotypic normal mouse, rabbit or goat immunoglobulin fraction at matched protein concentration. These were included for the examination of each specimen and consistently produced negative results.

\section{Results}

Histologically, all medulloblastoma tumours were composed of sheets or lobules of small cells with prominent nuclei and little cytoplasm. Two types of necrotic areas were stated.

In the first type, the area of dead cells was surrounded by undifferentiated medulloblastoma cells. The nuclei of these cells were compact, dark, round oval to somewhat elongated, or larger and more vesicular with distinct chromatin clumps. A lot of these cells expressed TLR 2 (Fig. 1A, B) and TLR 3 antigens (Fig. 1C). TLR 2 was also strongly and precisely expressed in the walls of dense network of capillaries that fulfil tumour regions 
Table I. Antibodies used in the study

\begin{tabular}{|c|c|c|c|c|c|}
\hline \multirow[t]{2}{*}{ Antibody } & \multirow[t]{2}{*}{ Type } & \multicolumn{2}{|c|}{ Antigen } & \multirow[t]{2}{*}{ Source } & \multirow[t]{2}{*}{ Dilution } \\
\hline & & Origin & Domain & & \\
\hline GFAP & monoclonal & human & full length & Santa Cruz & $1: 100$ \\
\hline GFAP & polyclonal & human & $\mathrm{N}$-terminus & Santa Cruz & $1: 100$ \\
\hline GFAP & polyclonal & human & C-terminus & Santa Cruz & $1: 100$ \\
\hline TLR 2 & polyclonal & human & $\mathrm{N}$-terminus & Santa Cruz & $1: 50$ \\
\hline TLR 3 & polyclonal & mouse & extracellular & Santa Cruz & $1: 50$ \\
\hline TLR 4 & polyclonal & human & $C$-terminus & Santa Cruz & $1: 50$ \\
\hline TLR 9 & polyclonal & human & near $N$-term & Santa Cruz & $1: 50$ \\
\hline Ferritin & polyclonal & human & full length & DAKO & $1: 100$ \\
\hline
\end{tabular}

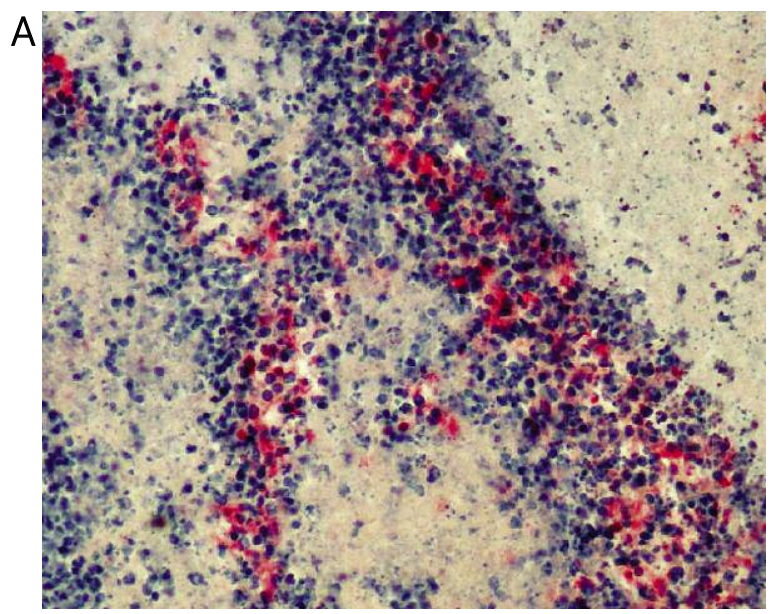

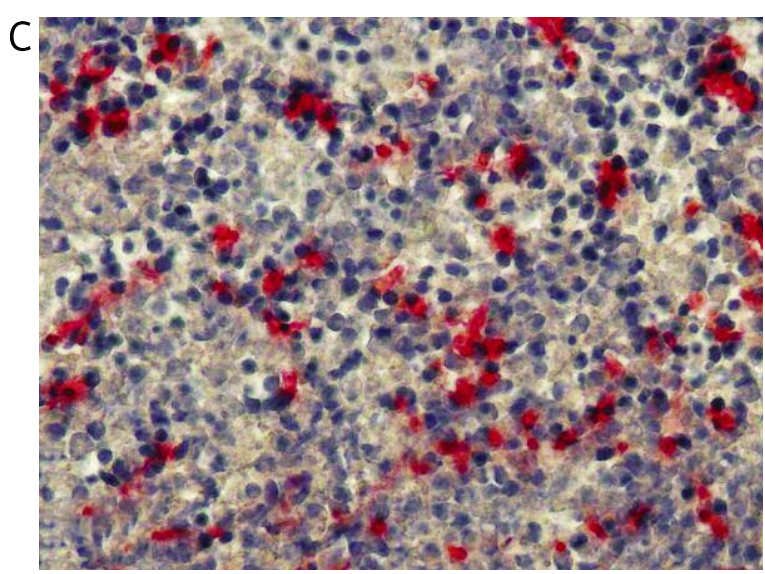

already cleared from dead cells (Fig. 2). In addition, some regions of solid tumour were patrolled by single TLR2 immuno-positive cells that were scattered throughout the neoplastic tissue (Table II).

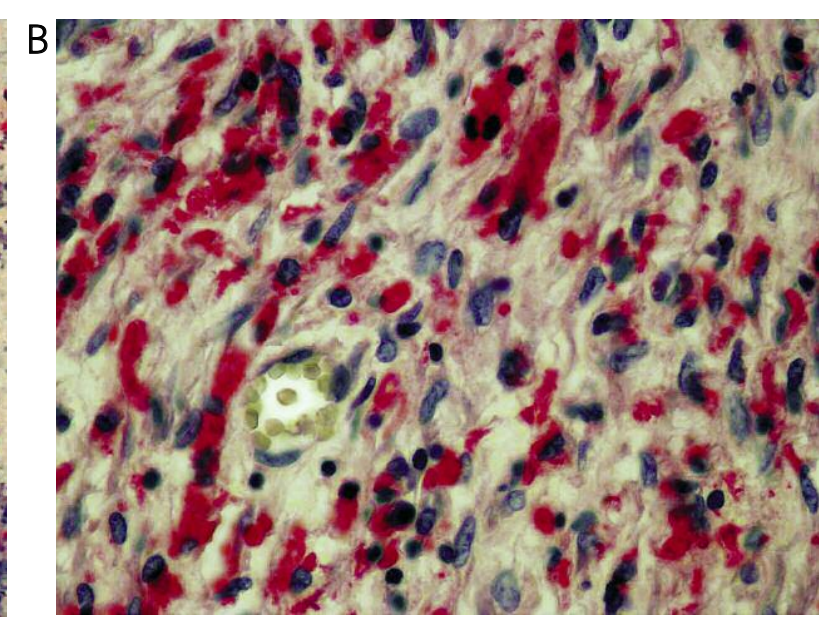

Fig. 1. Immunohistochemical staining for TLR 2 and TLR 3 in medulloblastoma. The panel demonstrates representative samples of TLR 2 immunopositive cells of the tumour in: (A) necrotic area of medulloblastoma, original magnification $\times 100$; $(B)$ at the periphery of medulloblastoma necrosis, original magnification $\times 400$; (C) TLR 3 immunopositive cells at the periphery of medulloblastoma necrosis, original magnification $\times 200$.

The second type of necrotic areas was found at the periphery of the tumour and composed of normal nerve tissue cells that undergo degeneration and/or characteristic morphological transformation into 


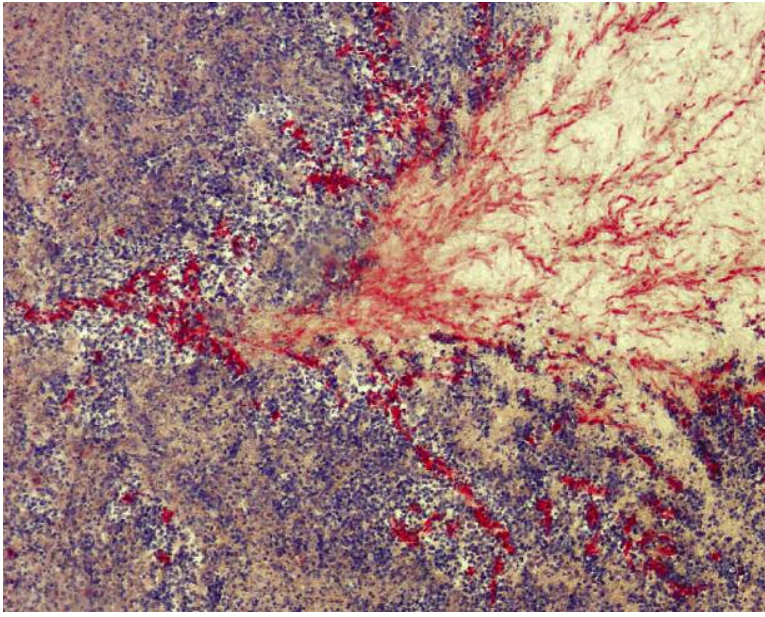

Fig. 2. TLR 2 strongly and precisely immunoexpressed on walls of blood vessels that fulfil tumour areas already cleared from dead cells; original magnification $\times 100$.

the hypertrophic glia cells. In all such hypertrophic cells or clumps of macrophages, TLR 2, TLR 3 and TLR 9 (Fig. 3A, B; Table II) were detected. No samples with brain medulloblastoma contained TLR 4.

\section{Discussion}

Inflammatory reaction is commonly associated with many types of neoplasms. Most tumours have antigenic qualities that are recognized by $T$ cells to provoke an immune response, which would be expected to eliminate or retard the tumour cells; by contrast, immunosuppression should increase the incidence of cancer [5]. A variety of clinical and experimental data seem to be in agreement with this theory of immune surveillance.
Results of our present study document that Tolllike receptors as receptors of innate immunity may play an important role in immune mechanisms of patients with medulloblastoma. We found that TLR 2 and TLR 3 were clearly associated with necrotic areas of medulloblastoma. Both receptors were precisely distributed on tumour cells around necrosis suggesting that in these undifferentiated cells, an innate immune system is present and can recognize pathogens delivered by dying cells. The nature of the pathogens remains unknown but it was previously documented that TLR 2 can bind pathogens such as lipoproteins/lipopeptides [3], peptidoglycan [23,26], lipoteichoic acid [23], lipoarabinomannan [20], phenol-soluble modulin [12], glycoinositolphospholipids [8], glycolipids [21], porins [18], atypical lipopolysaccharides [14,31], zymosan [28], all of them found in different microorganisms.

TLR 2 may bind also proteins delivered by necrotic host tissue [4].

In the presented study, a strong immunoexpression of TLR 2 on the wall of de novo formed blood vessels in medulloblastoma was found and suggests that TLR 2 plays an important role in tumour angiogenesis. Previously, the participation of TLR2 in neovascularization was observed during inflammation and wound healing process. Moreover, it has been documented that TLR 2 participated in such neovascularization after binding the end products of lipid oxidation that were accumulated at high levels during inflammation [32]. Thus, in our study, pathogens delivered by dying tumour cells of medulloblastoma may be similar in nature to those end products detected in inflammation.

Ligands for TLR 3 are less known than ligands for TLR 2 but they were characterized as double-stranded RNA molecules and the synthetic analogue polyino-

Table II. Distribution of innate immunity receptors - Toll-like receptors (TLR) in different compartments of the brain with medulloblastoma

\begin{tabular}{|ccccccc|}
\hline & \multicolumn{3}{c}{ Medulloblastoma } & & \multicolumn{2}{c|}{ Surrounding of medulloblastoma } \\
\cline { 2 - 4 } \cline { 6 - 7 } & Solid tumour & Necrosis & Necrosis boundary & & Normal tissue & Necrosis \\
\hline TLR 2 & $+(2)$ & $+++(2)$ & $++++(2)$ & $+(2)$ & 0 & $+++(1)$ \\
\hline TLR 3 & + & $+(2)$ & 0 & 0 & $++(1)$ \\
\hline TLR 4 & 0 & 0 & 0 & 0 & $+(1)$ \\
\hline TLR 9 & 0 & 0 & $++(2)$ & 0 \\
\hline
\end{tabular}

0 - lack of antigen in tissue sections; $+-<10 \% ;++-25-40 \%$; +++- 40-60\%; ++++-60-80\% of tumour cells (or nerve tissue cells). Numbers of immunopositive cells were counted in each of five serial sections under light microscope (magnification $\times 200$ ). In addition, immunohistochemical staining was graded for strength: 1 - weak reaction; 2 - strong reaction. Both strength and distribution estimation methods were previously described [17,25] 

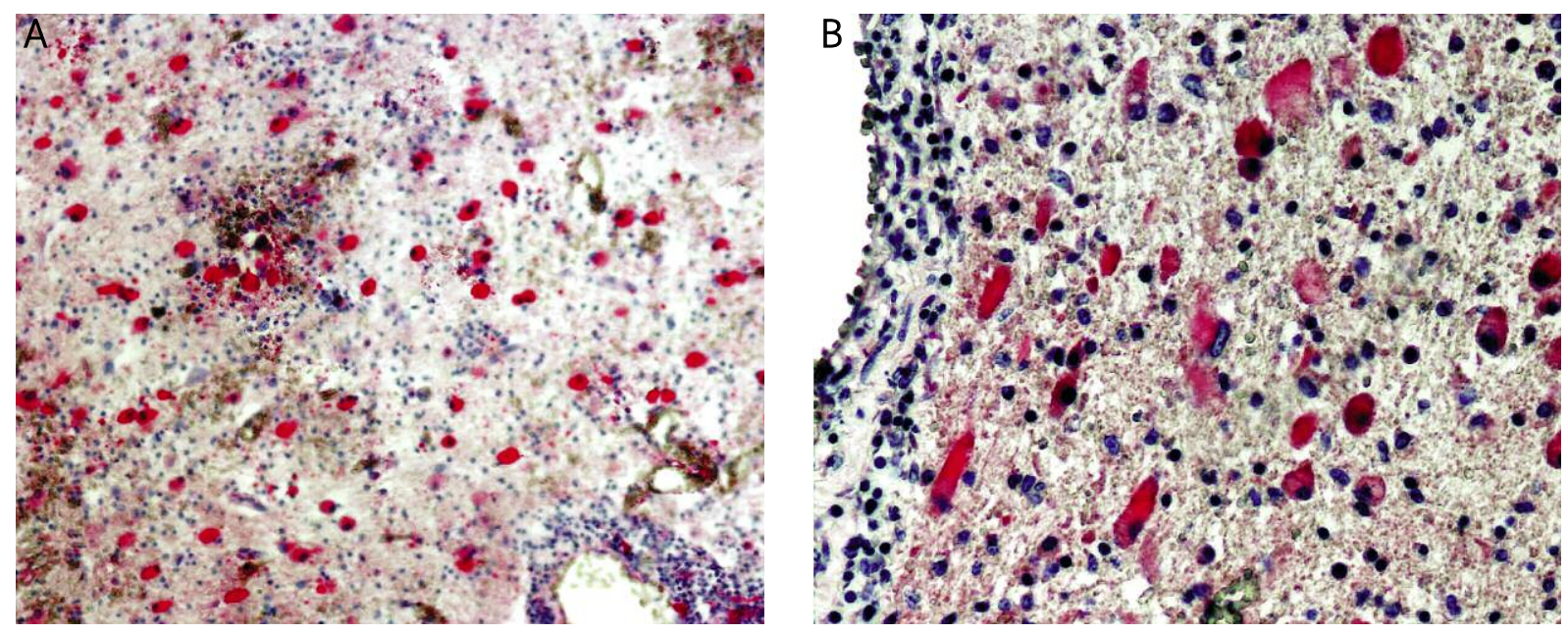

Fig. 3. Immunohistochemical staining for TLR 2 and TLR 3 cells of normal nerve tissue that undergo degeneration and/or characteristic morphological transformation into the hypertrophic glia cells. The panel demonstrates representative samples of: (A) TLR 2 immunopositive hypertrophic glia cells, original magnification $\times 100$, (B) TLR 3 immunopositive hypertrophic glia cells, original magnification $\times 200$.

sinic-polycytidylic acid, a viral RNA mimetic, has been shown to be a TLR3 agonist [2].

Results of our study suggest also that the activated innate immune system of tumour cells may initiate inflammatory response in the nervous tissue surrounding the tumour. It would be expected that the recognition of tumour pathogens by the receptors of the innate immune system will lead to an inflammatory response resulting in disruption of nervous tissue homeostasis at the tumour periphery.

Although the innate immune system has been regarded as a relatively nonspecific immunity, it is capable of differentiating between self and non-self. The innate immunity is present in the organism since birth, not requiring repeated exposure to pathogens, although it has a broad spectrum of resistance to infections and pathogens of tissue injury. Moreover, the innate immunity controls the adaptive immune system, which, in turn, has been developed by mammals as a more specific and complex but complementary defence system. The central nervous system (CNS), considered as an immunologically privileged organ, has well-organized innate immunity. The constitutively expressed TLRs were found in the regions devoid of the blood-brain barrier as circumventricular organs and in choroid plexus or leptomeninges. These receptors respond immediately to microbial pathogens circulating in the systemic infections or to endogenous pathogens released by necrotic tissue after trauma, transplantation or burns. Results of the present study show that such pathogens may be also produced by dead medulloblastoma cells. The role of TLRs in pathology of the CNS was a subject of numerous studies, which documented the implication of TLR 2 signalling in glia responses associated with repair by the clearance of myelin debris $[6,9,10]$.

The TLR 2 ligand peptidoglycan was detected in phagocytes functioning within multiple sclerosis lesions [22]. Administration of the TLR 2 ligand zymosan promoted regeneration after optic nerve crush injury [16], and systemic injection of the TLR 4 ligand - LPS accelerated myelin clearance in the injured spinal cord [30]. Direct injection of TLR ligands into the healthy brain or spinal cord induced robust inflammation that caused tissue damage [11,24].

In our patients the role of TLR 2-immunopositive cells, scattered throughout the solid tumour region of medulloblastoma is not known but they seem to patrol the tumour looking for ligands similar to those released by tumour necrotic areas. On the other hand, circulating pathogens may also activate endothelial and perivascular cells that produce soluble molecules into the brain parenchyma. These TLRs recognize the foreign invaders and during signalling transcription factors (nuclear factor-kB or interferon regulatory factor 3) are translocated into the cell nucleus to induce new genes that encode synthesis of various pro-inflammatory cytokines, enzymes and mediators [7,29]. The regulation of inflammation occurs on many levels, but the initial events are triggered upon TLR pathogen recognition. Since the 
proinflammatory molecules, when released in excess, may induce serious systemic disorders, organisms have evolved mechanisms for modulating their TLR-mediated responses [1]. The expression of TLR network in the CNS is dynamically regulated but may vary significantly in patients with neoplasm, depending on the state of the disease or effects of the treatment. Evidence now suggests that both innate and adaptive immune responses may initiate inflammation of the CNS. The spectrum of CNS diseases have syndromes of inflammatory and immune components. However, the direction that inflammation is taking may consequently be crucial for determining the ultimate outcome of insults in CNS. Recently, rapid progress has been made in our understanding of the molecular mechanisms of innate immunity; TLRs are suggested as potential therapeutic targets in the injured or diseased CNS.

The knowledge of the ligands, receptors and signalling pathways of innate immune responses during infections, inflammation and tumourigenesis provides new approaches for selective therapeutics.

Our findings show a new function of TLRs as sensors of pathogens released by medulloblastoma dead cells. This new function may provide a key link connecting innate immunity, neuroinflammation and angiogenesis in the tumour.

\section{References}

1. Akira S, Takeda K, Kaisho T. Toll-like receptors critical proteins linking innate and acquired immunity. Nature Immunol 2001; 2: 675-680.

2. Alexopoulou L, Holt AC, Medzhitov R, Flavell RA. Recognition of double-stranded RNA and activation of NF-kB by Toll-like receptor 3. Nature 2001; 413: 732-738.

3. Aliprantis AO, Yang RB, Mark MR, Suggett S, Devaux B, Radolf JD, Klimpel GR, Godowski P, Zychlinsky A. Cell activator and apoptosis by bacterial lipoproteins through Toll-like receptor 2. Science 1999 285: 736-739.

4. Asea A, Rehli M, Kabingu E, Boch JA, Bare O, Auron PE, Stevenson MA, Calderwood SK. Novel signal transduction pathway utilized by extracellular HSP70: role Toll-like receptor (TLR) 2 and TLR 4. J Biol Chem 2002; 277: 15028-15034.

5. Beverley P. Immunological memory in T cells. Curr Opin Immunol 1991; 3: 355-360.

6. Bechmann I, Nitsch R. Involvement of non-neuronal cells in entorhinal-hippocampal reorganization following lesions. Ann NY Acad Sci 2000; 911: 192-206.

7. Bowie A, O'Neill LA. The interleukin-1 receptor/toll-like receptor superfamily: signal generators for pro-inflammatory interleukins and microbial products. J Leukoc Biol 2000; 67: 508-514.

8. Coelho PS, Klein A, Talvani A, Coutinho SF, Takeuchi O, Akira S, Silva JS, Canizzaro H, Gazzinelli RT, Teixeira MM. Glycosylphospha- tidylinositol-anchored mucin-like glycoproteins isolated from Trypanosoma cruzi trypomastigotes induce in vivo leucocyte recruitment dependent on MCP-1 production by IFN-gamma-primedmacrophages. J Leukoc Biol 2002; 71: 837-844.

9. Drojdahl N, Hegelund IV, Poulsen FR, Wree A, Finsen B. Perforant path lesioning induces sprouting of CA3-associated fibre systems in mouse hippocampal formation. Exp Brain Res 2002; 144: 79-87.

10. Fenger C, Drojdahl N, Wirenfeldt M, Sylvest L, Jorgensen OS, Meldgaard M, Lambertsen KL, Finsen B. Tumor necrosis factor and its p55 and p75 receptors are not required for axonal lesion-induced microgliosis in mouse fascia dentate. Glia 2006; 54: 591-605.

11. Fitch MT, Doller C, Combs CK, Landreth GE, Silver J. Cellular and molecular mechanisms of glial scarring and progressive cavitation: in vivo and in vitro analysis of inflammation-induced secondary injury after CNS trauma. J Neurosci 1999; 19: 8182-8198.

12. Hajjar AM, O'Mahony DS, Ozinsky A, Underhill DM, Aderem A, Klebanoff SJ, Wilson CB. Cutting Edge: Functional interactions between Toll-like receptor (TLR) 2 and TLR 1 or TLR 6 in response to phenol-soluble modulin. J Immunol 2001; 166: 15-19.

13. Hanahan D, Weinberg RA. The hallmarks of cancer. Cell 2000; 100: $57-70$

14. Hirschfeld M, Weis JJ, Toshchakov V, Salkowski CA, Cody MJ, Ward DC, Qureshi N, Michalek SM, Vogel SN. Signaling by Toll-like receptor 2 and 4 agonists results in differential gene expression in murine macrophages. Infect Immunol 2001; 69: 1477-1482.

15. Kool M, Koster J, Bunt J, Hasselt NE, Lakeman A, van Sluis P, Troost D, Meeteren NS, Caron HN, Cloos J, Mrsić A, Ylstra B, Grajkowska W, Hartmann W, Pietsch T, Ellison D, Clifford SC, Versteeg R. Integrated genomics identifies five medulloblastoma subtypes with distinct genetic profiles, pathway signatures and clinicopathological features. PLoS One 2008; 3: e3088.

16. Leon S, Yin Y, Nguyen J, Irwin N, Benowitz LI. Lens injury stimulates axon regeneration in the mature rat optic nerve. J Neurosci 2000; 20: 4615-4626.

17. Maslinska D, Dambska M, Kaliszek A, Maslinski S. Accumulation, distribution and phenotype heterogeneity of mast cells $(M C)$ in human brains with neurocysticercosis. Folia Neuropathol 2001; 39: 7-13.

18. Massari P, Henneke P, Ho Y, Latz E, Golenbock DT, Wetzler LM. Cutting edge: Immune stimulation by neisserial porins is toll-like receptor 2 and MyD88 dependent. J Immunol 2002; 168: 1533-1537.

19. Means TK, Golenbock DT, Fenton MJ. Structure and function of Tolllike receptor proteins. Life Sci 2000; 68: 241-258.

20. Means TK, Wang S, Lien E, Yoshimura A, Golenbock DT, Fenton MJ. Human Toll- like receptors mediate cellular activation by Mycobacterium tuberculosis. J Immunol 1999; 163: 3920-3927.

21. Opitz B, Schröder NW, Spreitzer I, Michelsen KS, Kirschning CJ, Hallatschek W, Zähringer U, Hartung T, Göbel UB, Schumann RR. Tolllike receptor-2 mediates Treponema glycolipid and lipoteichoic acid-induced NF-kB translocation J Biol Chem 2001; 276: 2204122047.

22. Schrijver IA, van Meurs M, Melief MJ, Wim Ang C, Buljevac D, Ravid R, Hazenberg MP, Laman JD. Bacterial peptidoglycan and immune reactivity in the central nervous system in multiple sclerosis. Brain 2001; 124: 1544-1554.

23. Schwadner R, Dziarski R, Wesche H, Rothe M, Kirschning CJ. Peptidoglycan and lipoteichoic acid-induced cell activation is mediated by Toll-like receptor. J Biol Chem 1999; 274: 17406-17409. 
24. Szczepanik AM, Fishkin RJ, Rush DK, Wilmot CA. Effects of chronic intrahippocampal infusion of lipopolysaccharide in rat. Neuroscience 1996; 70: 57-65.

25. Tabori U, Baskin B, Shago M, Alon N, Taylor MD, Ray PN, Bouffet E, Malkin D, Hawkins C. Universal poor survival in children with medulloblastoma harboring somatic TP53 mutations. J Clin Oncol 2010; 28: 1345-1350.

26. Takeuchi O, Hoshino K, Kawai T, Sanjo H, Takada H, Ogawa T, Takeda K, Akira S. Differential roles of TLR 2 and TLR 4 in recognition of $\mathrm{G}$ ram-negative and Gram-positive cell wall components. Immunity 1999; 11: 443-451.

27. Thompson MC, Fuller C, Hogg TL, Dalton J, Finkelstein D, Lau CC, Chintagumpala M, Adesina A, Ashley DM, Kellie SJ, Taylor MD, Curran T, Gajjar A, Gilbertson RJ. Genomics identifies medulloblastoma subgroups that are enriched for specific genetic alterations. J Clin Oncol 2006; 24: 1924-1931.

28. Underhill DM, Ozinsky A, Hajjar AM, Stevens A, Wilson CB, Bassetti $M$, Aderem A. The Toll-like receptor 2 is recruited to macrophages phagosomes and discriminates between phatogens. Nature 1999; 401: 811-815.

29. Underhill DM, Ozinsky A. Toll-like receptors key mediators of microbe detection. Curr Opin Immunol 2002; 14: 103-110.

30. Vallieres N, Berard JL, David S, Lacroix S. Systemic injection of lipoplysaccharide accelerates myelin phagocytosis during Wallerian degeneration in the injured mouse spinal cord. Glia 2005; 53: 103-113.

31. Werts C, Tapping RI, Mathison JC, Chuang TH, Kravchenko V, Saint Girons I, Haake DA, Godowski PJ, Hayashi F, Ozinsky A, Underhill DM, Kirschning CJ, Wagner H, Aderem A, Tobias PS, Ulevitch RJ. Leptospiral lipopolysaccharide activates cells through a TLR 2-dependent mechanism. Nat Immunol 2001; 2: 346-352.

32. West XZ, Malinin NL, Merkulova AA, Tischenko M, Kerr BA, Borden EC, Podrez EA, Salomon RG, Byzova TV. Oxidative stress induces angiogenesis by activating TLR 3 with novel endogenous ligands. Nature 2010; 467: 972-976. 